\title{
Ractopamina em dietas para suínos machos imunocastrados, castrados e fêmeas
}

\author{
Ractopamine in diets for immunocastrated, barrows and females
}

\author{
Eleíza Moraes $^{\mathrm{I}}$ Charles Kiefer $^{\mathrm{II} *}$ Iandara Schettert Silva $^{\mathrm{II}}$
}

\section{RESUMO}

O objetivo do trabalho foi avaliar o desempenho e as características quantitativas de carcaça de suínos machos imunocastrados, castrados e fêmeas, na fase de terminação, alimentados com dietas contendo $10 \mathrm{ppm}$ de ractopamina.

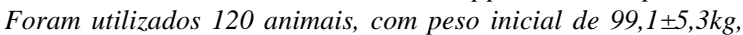
distribuídos em delineamento de blocos ao acaso, em esquema fatorial $2 \times 3$ (dois níveis de ractopamina, 0 e 10ppm e três sexos), cinco repetições com quatro animais cada. A inclusão de 10 ppm de ractopamina na dieta melhorou $(P<0,05)$ a conversão alimentar dos suínos, independentemente do sexo. A inclusão de ractopamina prejudicou $(P<0,05)$ o ganho de peso dos machos imunocastrados e aumentou $(P<0,05)$ o ganho de peso dos machos castrados e das fêmeas, sem, no entanto, afetar $(P>0,05)$ as características quantitativas de carcaça dos suínos. O sexo foi determinante para o desempenho e as características quantitativas de carcaça; as fêmeas apresentaram rendimento de carcaça quente superior $(P<0,05)$ aos machos imunocastrados, que apresentaram rendimento superior $(P<0,05)$ aos machos castrados. Os machos imunocastrados $e$ as fêmeas apresentaram maior $(P<0,05)$ percentual de carne magra em relação aos machos castrados. Os resultados desta pesquisa evidenciam a necessidade de estudos visando à adequação dos níveis nutricionais das dietas contendo ractopamina para suínos imunocastrados.

Palavras-chave: aditivos, beta-agonistas, carcaça, desempenho, imunocastração.

\section{ABSTRACT}

The objective of this study was to evaluate the performance and the quantitative characteristics of carcass of immunocastrated, barrows and females in the finishing phase fed with diets containing 10ppm of ractopamine. One hundred and twenty animals were used, with initial weight of $99.1 \pm 5.3 \mathrm{~kg}$, distributed in a randomized blocks factorial design in $2 \times 3$ (two ractopamine levels, 0 and 10ppm and three sex), five replicates of four animals each. The inclusion of $10 \mathrm{ppm}$ of ractopamine in the diet improved $(P<0.05)$ feed conversion in pigs, independent of sex. The inclusion of ractopamine damaged $(P<0.05)$ the weight gain of the immunocastrated and increased $(P<0.05)$ the weight gain of the barrows and the females, without, however, affect $(P>0.05)$ quantitative carcass characteristics of pigs. The sex was determining factor in performance and carcass quantitative traits and the females had higher $(P<0.05)$ hot carcass yield for immunocastrated male and they have yield above $(P<0.05)$ the barrows. Immunocastrated males and females had higher $(P<0.05)$ percentage of lean meat for barrows. The results of this study highlight the need for studies to adjust the nutrient levels of diets containing ractopamine to immunocastrated pigs.

Key words: additives, beta-agonists, carcass, performance, immunocastration.

\section{INTRODUÇÃO}

Com a aprovação do uso de ractopamina como aditivo nas dietas dos suínos, tem-se a disposição uma alternativa para potencializar o desempenho e aumentar a produção de carne suína brasileira. A inclusão de ractopamina nas dietas de suínos na fase de terminação melhora significativamente o ganho de peso e a conversão alimentar e reduz o consumo de ração (CROME et al., 1996). O consumo de ractopamina melhora a qualidade da carcaça de suínos, pois reduz a espessura de toucinho, aumenta a profundidade de lombo e a deposição de carne magra (MARINHO et al., 2007). Contudo, não afeta a qualidade da carne suína em termos de cor, marmoreio, firmeza e pH (HERR et al., 2000).

ISuinocultura Rancho Alegre, Campo Grande, MS, Brasil.

"Universidade Federal de Mato Grosso do Sul (UFMS), 79074-460, Campo Grande, MS, Brasil. E-mail: charles@nin.ufms.br.

*Autor para correspondência. 
Vários estudos (DUNSHEA et al., 1993; UTTARO et al., 1993 e WILLIAMS et al., 1994) têm avaliado o efeito da inclusão de ractopamina na dieta em função do sexo dos suínos. De uma maneira geral, constata-se que a ractopamina propicia respostas semelhantes em termos de taxa de crescimento, consumo de ração e deposição de tecido muscular na carcaça, tanto em machos castrados como em fêmeas (UTTARO et al., 1993). Por outro lado, quando se relaciona o desempenho de suínos machos inteiros, castrados e fêmeas, tem-se constatado que a ractopamina aumenta o ganho de peso nos machos castrados e nas fêmeas, mas não nos machos inteiros (DUNSHEA et al., 1993). Esses resultados podem indicar que, assim como os suínos machos inteiros, os machos imunocastrados podem não apresentar respostas à inclusão de ractopamina na dieta.

A imunocastração é uma alternativa que vem sendo muito utilizada na produção mundial de suínos em substituição ao método tradicional de castração cirúrgica dos machos. Defini-se imunocastração como um método de castração por meio de vacina anti-GnRF (fator liberador de gonadotropinas), que inibe o início da puberdade, evita o odor e o sabor característico de macho inteiro na carne, melhora o desempenho e as características quantitativas de carcaça (DUNSHEA et al., 2001; JAROS et al., 2005). Além disso, reduz o comportamento agressivo dos machos (CRONIN et al., 2003) e respeita o bem-estar dos animais.

Considerando o crescimento da imunocastração de suínos no Brasil, associado à carência de informações sobre o efeito da ractopamina na dieta desses animais em relação aos demais sexos, propôs-se realizar esta pesquisa. Este estudo teve, portanto, como objetivo avaliar a inclusão de 10ppm de ractopamina em dietas para suínos machos imunocastrados, castrados e fêmeas, em fase de terminação, sobre o desempenho e as características quantitativas de carcaça.

\section{MATERIAL E MÉTODOS}

O experimento foi realizado na Suinocultura Rancho Alegre, localizada no município de Campo Grande, Mato Grosso do Sul (MS). Foram utilizados 120 suínos, sendo 40 machos imunocastrados, 40 machos castrados e 40 fêmeas, Duroc/Pietran x Large White/Landrace, com peso médio inicial de 99,1+5,3kg. Os animais foram distribuídos em delineamento experimental, em blocos ao acaso, em esquema fatorial 2x3 (dois níveis de ractopamina, 0 e 10ppm e três sexos), cinco repetições, sendo cada unidade experimental constituída por quatro animais. Na formação dos blocos, levou-se em consideração o peso inicial dos animais.

Os suínos machos foram submetidos ao procedimento cirúrgico ao sétimo dia de vida para a obtenção dos machos castrados. Para a obtenção dos animais imunocastrados, os suínos machos inteiros foram submetidos a duas doses de $2 \mathrm{~mL}$ de vacina, com aplicação subcutânea, sendo a primeira 60 dias antes do abate quando os animais estavam com 100 dias de vida, e a segunda 30 dias antes do abate quando os animais estavam com 137 dias de idade, ocasião do início do período experimental. Para a realização da imunocastração, foi utilizada vacina específica à base de um análogo sintético incompleto do GnRF conjugado a uma proteína carreadora.

As dietas experimentais (Tabela 1) foram isonutritivas, preparadas à base de milho, farelo de soja e farinha de carne e ossos e suplementadas com minerais e vitaminas. Os níveis de ractopamina foram obtidos a partir da inclusão de cloridrato de ractopamina em substituição ao caulim. As rações e a água foram fornecidas à vontade aos animais durante todo o período experimental.

Foram coletados diariamente os resíduos de ração do chão que foram somados às sobras do comedouro ao final do período experimental, determinando-se dessa forma o consumo de ração diário. A pesagem dos animais foi realizada no início e no final do experimento, visando à obtenção dos dados relativos ao ganho de peso diário e à conversão alimentar.

O período experimental teve duração de 30 dias, e os animais foram abatidos com 167 dias de vida. Ao final do período experimental, os animais foram pesados, submetidos ao jejum de sólidos de 24 horas, embarcados em caminhão e transportados para o frigorífico Aurora, localizado no Município de São Gabriel do Oeste.

No abatedouro, os suínos foram pesados e alojados em baias coletivas de espera com acesso à vontade a água. Por ocasião do abate, os suínos foram insensibilizados pelo método elétrico (eletronarcose) e, posteriormente, sangrados, escaldados e eviscerados. Na linha de abate, foram obtidos o peso de carcaça quente e a percentagem de carne magra por meio de sonda eletrônica na região de inserção da última vértebra torácica com a primeira lombar a seis centímetros da linha média de corte da carcaça (ponto $\mathrm{P}_{2}$ ).

O rendimento de carcaça foi calculado com base no peso de abatedouro e no peso de carcaça quente. O índice de bonificação foi estimado com base nos parâmetros obtidos no ponto $\mathrm{P}_{2}$ das carcaças. 
Tabela 1 - Composição centesimal e nutricional das dietas experimentais.

\begin{tabular}{|c|c|c|}
\hline \multirow{2}{*}{ Ingredientes } & \multicolumn{2}{|c|}{$\begin{array}{l}\text { Níveis de ractopamina, } \\
\text { ppm }\end{array}$} \\
\hline & 0 & 10 \\
\hline Milho & 73,80 & 73,80 \\
\hline Farelo de soja (46\%) & 15,40 & 15,40 \\
\hline Farinha de carne e ossos (42\%) & 4,90 & 4,90 \\
\hline Banha & 2,30 & 2,30 \\
\hline Casca de soja & 1,00 & 1,00 \\
\hline Calcário & 1,32 & 1,32 \\
\hline Suplemento vitamínico e mineral ${ }^{1}$ & 0,15 & 0,15 \\
\hline Sal comum & 0,60 & 0,60 \\
\hline L-Lisina $\mathrm{HCl}$ & 0,48 & 0,48 \\
\hline Caulim & 0,05 & 0,00 \\
\hline Ractopamina & 0,00 & 0,05 \\
\hline TOTAL & 100,00 & 100,00 \\
\hline Proteína bruta (\%) & 15,63 & 15,63 \\
\hline Energia Metabolizável (kcal kg-1) & 3.256 & 3.256 \\
\hline Fibra bruta & 2,44 & 2,44 \\
\hline Lisina digestível (\%) & 0,98 & 0,98 \\
\hline Metionina +Cistina digestível (\%) & 0,45 & 0,45 \\
\hline Treonina digestível (\%) & 0,48 & 0,48 \\
\hline Triptofano digestível (\%) & 0,14 & 0,14 \\
\hline Cálcio (\%) & 0,48 & 0,48 \\
\hline Fósforo disponível (\%) & 0,25 & 0,25 \\
\hline Sódio (\%) & 0,28 & 0,28 \\
\hline
\end{tabular}

${ }^{1}$ Conteúdo por quilograma de produto: Cobre, 30.000mg; Zinco, $160.000 \mathrm{mg} ;$ Iodo, 1.900mg; Ferro, 100.000mg; Manganês, 70.000mg; Vit. A 840.000UI; Vit D3, 210.000UI; Vit. E, 1.522,5mg; Ácido fólico, 63mg; Pantotenato de Cálcio, 1.680mg; Biotina, 5,25mg; Niacina, 2.520mg; Piridoxina, 210mg; Riboflavina, 588mg; Tiamina, 210mg; Vit. B12, 3.150mg; Vit. K3, 105mg; Selênio, 63mg; Colina, 65.250mg; veículo q.s.p.1000g.

As variáveis avaliadas foram as de desempenho (peso final, ganho de peso, consumo de ração e conversão alimentar), as características quantitativas de carcaça (peso de carcaça quente, rendimento de carcaça quente e percentual de carne magra) e o índice de bonificação.

Os dados obtidos foram tabulados e submetidos à análise de variância e ao teste Tukey para comparação de médias, ao nível de 5\% de significância, utilizando-se o programa estatístico SAS (2002).

\section{RESULTADOS E DISCUSSÃO}

Os resultados de desempenho dos suínos estão apresentados na tabela 2. Não foi constatada interação $(\mathrm{P}>0,05)$ entre níveis de ractopamina e sexo para peso final, consumo de ração diário e conversão alimentar dos animais. Não foi observado efeito $(\mathrm{P}>0,05)$ dos tratamentos sobre o peso final dos suínos.

Foi constatada interação significativa $(\mathrm{P}<0,05)$ entre os níveis de ractopamina e o sexo dos suínos, e a inclusão de ractopamina na dieta resultou em maior $(\mathrm{P}<0,05)$ ganho de peso dos suínos machos castrados em relação aos machos imunocastrados e às fêmeas. Quando os animais foram alimentados com a dieta não suplementada com ractopamina, verificou-se que os machos imunocastrados apresentaram ganho de peso superior $(\mathrm{P}<0,05)$ em relação aos machos castrados e estes apresentaram ganho superior $(\mathrm{P}<0,05)$ em relação ao das fêmeas.

Quando se avaliou a inclusão de ractopamina em cada um dos sexos, verificou-se que os suínos machos imunocastrados alimentados com dieta contendo ractopamina apresentaram menor $(\mathrm{P}<0,05)$ ganho de peso em relação aos não suplementados. Por outro lado, os machos castrados e as fêmeas suplementadas com o aditivo apresentaram ganho de peso superior $(\mathrm{P}<0,05)$ quando comparados as mesmas categorias não suplementadas.

Assim, de acordo com os resultados obtidos, pode-se inferir que a inclusão de 10ppm de ractopamina na dieta melhorou o ganho de peso diário dos suínos machos castrados e das fêmeas, porém prejudicou o ganho de peso dos machos imunocastrados. Uma possível explicação para esse resultado pode estar relacionada com a exigência nutricional diferenciada entre as categorias avaliadas, uma vez que, possivelmente, os suínos machos imunocastrados apresentam exigência aminoacídica semelhante a dos machos inteiros. Os machos inteiros, por sua vez, apresentam exigência aminoacídica superior em relação às fêmeas e aos machos castrados (XUE et al., 1997); dessa forma, é provável que a concentração aminoacídica da dieta experimental tenha sido insuficiente para atender a demanda biológica de crescimento dessa categoria, quando alimentada com a dieta contendo ractopamina.

Além disso, tem-se constatado que a resposta à inclusão de ractopamina na dieta dos suínos é influenciada pelos níveis de aminoácidos. Os animais que recebem o aditivo e tem em suas dietas baixos níveis de aminoácidos podem apresentar menor desempenho quando comparados aos animais que sequer recebem a ractopamina. Isso pode ser explicado pelo fato de que a ractopamina pode diminuir o consumo de ração e, consequentemente, o consumo de aminoácidos, limitando assim o potencial de resposta do animal (SCHINCKEL et al., 2003). 
Tabela 2 - Desempenho de suínos machos imunocastrados (MI), castrados (MC) e fêmeas (F) alimentados com dieta contendo ractopamina (RAC).

\begin{tabular}{|c|c|c|c|c|c|c|c|c|}
\hline \multirow{2}{*}{ Variáveis } & \multirow{2}{*}{ RAC, ppm } & \multicolumn{3}{|c|}{------------------------Sexo----------------------- } & \multirow{2}{*}{ Média } & \multicolumn{3}{|c|}{-------------------------> P------------------------ } \\
\hline & & MI & MC & $\mathrm{F}$ & & Sexo & RAC & Sexo x RAC \\
\hline \multirow[t]{3}{*}{$\mathrm{PF}, \mathrm{kg}$} & 0 & 123,25 & 119,00 & 115,10 & 119,13 & 0,10 & 0,21 & 0,32 \\
\hline & 10 & 121,41 & 124,40 & 119,53 & 121,60 & & & \\
\hline & Média & 122,43 & 121,70 & 117,31 & & & & \\
\hline \multirow[t]{3}{*}{ GPD, kg } & 0 & 0,86Aa & 0,69Bb & $0,61 \mathrm{Cb}$ & 0,72 & 0,11 & 0,17 & 0,05 \\
\hline & 10 & $0,74 \mathrm{Bb}$ & 0,88Aa & 0,75Aa & 0,79 & & & \\
\hline & Média & 0,81 & 0,79 & 0,68 & & & & \\
\hline \multirow[t]{3}{*}{ CRD, kg } & 0 & 3,41 & 2,99 & 2,61 & 3,00 & 0,02 & 0,52 & 0,46 \\
\hline & 10 & 3,26 & 3,21 & 2,80 & 3,07 & & & \\
\hline & Média & $3,30 \mathrm{~A}$ & $3,10 \mathrm{~B}$ & $2,70 \mathrm{C}$ & & & & \\
\hline \multirow[t]{3}{*}{$\mathrm{CA}, \mathrm{kg} \mathrm{kg}^{-1}$} & 0 & 4,24 & 4,46 & 4,09 & $4,25 b$ & 0,33 & 0,05 & 0,09 \\
\hline & 10 & 4,32 & 3,51 & 3,86 & $3,89 a$ & & & \\
\hline & Média & 4,27 & 3,99 & 3,97 & & & & \\
\hline
\end{tabular}

PF (peso final); GPD (ganho de peso diário); CRD (consumo de ração diário); CA (conversão alimentar).

As médias seguidas de pelo menos uma mesma letra maiúscula, nas linhas, não diferem entre si ao nível de 5\% de probabilidade, pelo teste de Tukey.

As médias seguidas de pelo menos uma mesma letra minúscula, nas colunas, não diferem entre si ao nível de 5\% de probabilidade, pelo teste F.

Resultado semelhante ao obtido neste estudo para ganho de peso foi obtido por DUNSHEA et al. (1993), quando avaliaram a suplementação de 20ppm de ractopamina na dieta de suínos machos inteiros, castrados e fêmeas e verificaram que a inclusão de ractopamina na dieta promoveu aumento de $21 \mathrm{e}$ $17 \%$ do ganho de peso nos suínos castrados e nas fêmeas, respectivamente, enquanto que o ganho de peso dos machos inteiros não foi alterado pela inclusão de ractopamina em relação à dieta controle. De acordo com os pesquisadores, uma hipótese para essa resposta pode ter sido a limitação proteica da dieta, uma vez que os machos inteiros apresentaram aumento de $15 \%$ na deposição diária de proteína na carcaça, enquanto que os machos castrados e as fêmeas apresentaram aumento superior a $40 \%$ na deposição proteica diária em função da inclusão de ractopamina na dieta.

Observou-se efeito $(\mathrm{P}<0,05)$ do sexo sobre o consumo diário de ração dos suínos, em que os machos imunocastrados apresentaram consumo superior ao dos machos castrados que, por sua vez, apresentaram consumo superior ao das fêmeas.

Foi constatado efeito $(\mathrm{P}<0,05)$ dos níveis de ractopamina sobre a conversão alimentar dos suínos, e os animais alimentados com a dieta contendo ractopamina apresentaram melhor conversão alimentar em relação àqueles alimentados com a dieta controle.
Melhores resultados para a conversão alimentar também foram verificados por MARINHO et al. (2007), que observaram melhora de $12,5 \%$ quando as dietas dos suínos em terminação foram suplementadas com 5ppm de ractopamina em relação ao grupo controle. Efeitos positivos da suplementação de ractopamina também foram relatados por CROME et al. (1996), que obtiveram melhora de 18,6\% na eficiência alimentar de suínos abatidos aos $125 \mathrm{~kg}$ e suplementados com 20ppm do aditivo.

De acordo com PEREIRA et al. (2008), a melhora na conversão alimentar dos suínos alimentados com dietas contendo ractopamina pode ser justificada pelo aumento da eficiência de utilização dos nutrientes da dieta, que ocorre devido a um favorecimento da deposição proteica na carcaça pela ação metabólica do aditivo.

Na tabela 3, estão apresentadas as características quantitativas de carcaça dos suínos. Não foi constatada interação $(\mathrm{P}>0,05)$ entre os níveis de ractopamina e o sexo dos animais sobre os parâmetros quantitativos de carcaça avaliados.

A inclusão de 10ppm de ractopamina na dieta dos suínos não influenciou $(\mathrm{P}>0,05)$ as características quantitativas das carcaças. Em contraste com os resultados obtidos neste estudo, vários pesquisadores (MARINHO et al., 2007; PEREIRA et al., 2008; 
Tabela 3 - Características de carcaça de suínos machos imunocastrados (MI), castrados (MC) e fêmeas (F) alimentados com dieta contendo ractopamina (RAC).

\begin{tabular}{|c|c|c|c|c|c|c|c|c|}
\hline \multirow{2}{*}{ Variáveis } & \multirow{2}{*}{ RAC, ppm } & & & & \multirow[b]{2}{*}{ Média } & \multicolumn{3}{|c|}{-------------------------'> P------------------------- } \\
\hline & & MI & MC & $\mathrm{F}$ & & Sexo & RAC & Sexo $x$ RAC \\
\hline \multirow[t]{3}{*}{ PCQ, kg } & 0 & 85,27 & 87,15 & 83,56 & 85,19 & 0,78 & 0,32 & 0,13 \\
\hline & 10 & 88,06 & 84,10 & 87,24 & 86,52 & & & \\
\hline & Média & 86,51 & 85,63 & 85,40 & & & & \\
\hline \multirow[t]{3}{*}{ RCQ, kg } & 0 & 70,55 & 72,60 & 72,59 & 71,86 & 0,01 & 0,71 & 0,11 \\
\hline & 10 & 72,78 & 68,16 & 73,67 & 71,70 & & & \\
\hline & Média & $71,54 b$ & 70,38c & 73,13a & & & & \\
\hline \multirow[t]{3}{*}{ CM, \% } & 0 & 58,10 & 57,16 & 58,73 & 58,06 & 0,05 & 0,88 & 0,39 \\
\hline & 10 & 58,47 & 57,47 & 58,01 & 57,98 & & & \\
\hline & Média & $58,26 a$ & $57,32 b$ & $58,37 \mathrm{a}$ & & & & \\
\hline \multirow[t]{3}{*}{ IBC } & 0 & 111,43 & 109,45 & 112,50 & 111,25 & 0,14 & 0,64 & 0,15 \\
\hline & 10 & 111,50 & 110,52 & 110,43 & 110,79 & & & \\
\hline & Média & 111,46 & 109,98 & 111,46 & & & & \\
\hline
\end{tabular}

PCQ (peso de carcaça quente); RCQ (rendimento de carcaça quente); CM (percentual de carne magra); IB (Índice de bonificação das carcaças).

As médias seguidas pela mesma letra, nas linhas, não diferem entre si ao nível de 5\% de probabilidade, pelo teste de Tukey.

SANCHES et al., 2009) constataram melhora significativa das características quantitativas de carcaça, principalmente em relação ao aumento da percentagem de carne magra. De acordo com SCHINCKEL et al. (2003), a ractopamina reduz a síntese de ácidos graxos no tecido adiposo e ao mesmo tempo aumenta a síntese proteica, fato que resulta na melhora do percentual de carne magra da carcaça.

Também não houve efeito $(\mathrm{P}>0,05)$ do sexo dos animais sobre o peso de carcaça quente e sobre o índice de bonificação das carcaças. Por outro lado, verificou-se efeito $(\mathrm{P}<0,05)$ do sexo dos suínos sobre o rendimento de carcaça quente, e as fêmeas apresentaram rendimento superior ao dos machos imunocastrados e estes apresentaram rendimento superior ao dos machos castrados.

Observou-se efeito $(\mathrm{P}<0,05)$ do sexo dos animais sobre o percentual de carne magra da carcaça; os suínos imunocastrados e as fêmeas apresentaram percentual de carne magra superior ao dos machos castrados. Estes resultados estão de acordo com os obtidos por BALL et al. (1996), que observaram superioridade de 6,3\% de carne magra nos suínos machos inteiros em relação aos castrados. Revisando a literatura, XUE et al. (1997) constataram que os suínos machos inteiros apresentam deposição de proteína na carcaça superior aos machos castrados, o que resulta em aumento do percentual de carne magra da carcaça. Da mesma forma, vários pesquisadores (CROMWELL et al., 1993; EGGERT et al., 1996; WAGNER et al., 1999; ANTUNES et al., 2001) verificaram maior percentual de carne magra das fêmeas em relação aos machos castrados.

\section{CONCLUSÕES}

A inclusão de 10ppm de ractopamina na dieta melhora a conversão alimentar dos suínos, independentemente do sexo. A inclusão de ractopamina prejudica o ganho de peso dos machos imunocastrados e aumenta o ganho de peso dos machos castrados e das fêmeas, sem, no entanto, afetar as características quantitativas de carcaça dos suínos.

O sexo dos suínos é determinante do desempenho e das características quantitativas de carcaça; as fêmeas apresentam rendimento de carcaça quente superior aos machos imunocastrados, que apresentam rendimento superior aos machos castrados. Os machos imunocastrados e as fêmeas apresentam maior percentual de carne magra em relação aos machos castrados.

Os resultados desta pesquisa evidenciam a necessidade de estudos visando à adequação dos níveis nutricionais das dietas contendo ractopamina para suínos imunocastrados. 


\section{REFERÊNCIAS}

ANTUNES, R.C. et al. O efeito do genótipo HAL sobre o rendimento de carne em partes da carcaça de suínos cruzados. Revista TeC Carnes, v.3, p.1-15, 2001.

BALL, R.O. et al. Differences among breeds, breed origins and gender for growth, carcass composition and pork quality. 1996. Disponível em: <http://www.nsif.com/conferences/1996/ opcap2.htm>. Acesso em: 22 fev. 2009.

CROME, P.K. et al. Effect of ractopamine on growth performance, carcass composition, and cutting yields of pigs slaughtered at 107 and 125 kilograms. Journal of Animal Science, v.74, p.709-716, 1996. Disponível em: <http:// jas.fass.org/cgi/reprint/74/4/709.pdf>. Acesso em: 10 nov. 2008.

CROMWELL, G.L. et al. The dietary protein and (or) lysine requirements of barrows and gilts. Journal of Animal Science, v.71, p.1510-1519, 1993.

CRONIN, G.M. et al. The effects of immuno- and surgicalcastration on the behaviour and consequently growth of grouphoused, male finisher pigs. Applied Animal Behaviour Science, v.81, p.111-126, 2003. Disponível em: <http:// w w w. S c i e $\mathrm{n}$ c e d i r e c t . c o m/ science?_ob=MImg\&_imagekey=B6T48-47HS813-2$19 \&$ \& c d i $=4968 \&$ \& us e r $=686415 \&$ \& orig $=$ se arch \&_cover Dat e $=04 \% 2$ F $19 \% 2$ F $2003 \&$ \& s k = 999189997 \& vi e w = c \& w c h p =d G L b V l z zSkWb\&md5=04e61ce9739a76bd04939460ad244e49\&ie=/ sdarticle.pdf>. Acesso em: 10 nov. 2008. doi: 10.1016/S01681591(02)00256-3.

DUNSHEA, F.R. et al. Vaccination of boars with a GnRH vaccine (Improvac) eliminates boar taint and increases growth performance. Journal of Animal Science, v.79, p.25242535, 2001. Disponível em: <http://jas.fass.org/cgi/reprint/ 79/10/2524.pdf>. Acesso em: 12 nov. 2008.

DUNSHEA, F.R. et al. Interrelationships between sex and ractopamine on protein and lipid deposition in rapidly growing pigs. Journal of Animal Science, v.71, p.2919-2930, 1993. Disponível em: <http://www.animal-science.org/cgi/reprint/71/ 11/2919.pdf>. Acesso em: 15 nov. 2008.

EGGERT, J.M. et al. Effects of genotype, sex, slaughter weight, and dietary fat on pig growth, carcass composition, and pork quality. Purdue University Swine Day, p.1-6, 1996. Disponível em: <http://www.ansc.purdue.edu/swine/swineday/ sday96/psd12-96.htm>. Acesso em: 10 nov. 2008. 1996.

HERR, C.T. et al. Effect of nutritional level while feeding paylean to late-finishing swine. Purdue University Swine Day, p.89-95, 2000. Disponível em: <http:// www.ansc.purdue.edu/swine/swineday/sday00/16.pdf $>$. Acesso em: 10 nov. 2008.

JAROS, P. et al. Effect of active immunization against GnRH on androstenone concentration, growth performance and carcass quality in intact male pigs. Livestock Production Science, v.92, p.31-38, 2005.

MARINHO, P.C. et al. Efeito da ractopamina e de métodos de formulação de dietas sobre o desempenho e as características de carcaça de suínos machos castrados em terminação. Revista Brasileira de Zootecnia, v.36, p.1061-1068, 2007. Disponível em: <http://www.scielo.br/pdf/rbz/v36n4s0/11.pdf>. Acesso em: 12 nov. 2008. doi: 10.1590/S151635982007000500011 .

PEREIRA, F.A. et al. Efeitos da ractopamina e de dois níveis de lisina digestível na dieta sobre o desempenho e características de carcaça de leitoas em terminação. Arquivo Brasileiro de Medicina Veterinária e Zootecnia, v.60, p.943-952, 2008. Disponível em: <http://www.scielo.br/pdf/abmvz/v60n4/25.pdf>. Acesso em: 12 nov. 2008. doi: 10.1590/S010209352008000400025 .

SANCHES, J.F. Níveis de ractopamina nas dietas de suínos machos castrados na fase de terminação. 2009. 44f. Dissertação (Mestrado em Ciência Animal) - Curso de Pósgraduação em Ciência Animal, Universidade Federal de Mato Grosso do Sul.

SAS Institute. SAS user's guide: statistic, version 8.2, 6.ed. Cary, NC, 2001. Todd and Browde.

SCHINCKEL, A.P. et al. Development of a model to describe the compositional growth and dietary lysine requirements of pigs fed ractopamine. Journal of Animal Science, v.81, p.1106-1119, 2003. Disponível em: <http://jas.fass.org/cgi/ reprint/81/5/1106.pdf>. Acesso em: 15 nov. 2008.

UTTARO, B.E. et al. Effect of ractopamine and sex on growth, carcass characteristics, processing yield and meat quality characteristics of crossbred swine. Journal of Animal Science, v.71, p.2439-3449, 1993. Disponível em: <http://jas.fass.org/ cgi/reprint/71/9/2439.pdf>. Acesso em: 12 nov. 2008.

WILLIAMS, N.H. et al. The impact of ractopamine, energy intake and dietary fat on finisher pig growth performance and carcass merit. Journal of Animal Science, v.72, p.31523162, 1994. Disponível em: <http://jas.fass.org/cgi/reprint/ 72/12/3152.pdf $>$. Acesso em: 10 nov. 2008.

XUE, J.L. et al. Performance, carcass, and meat quality advantages of boars over barrow: a literature review. Swine Health and Production, v.5, p.21-28, 1997. Disponível em: $<$ http://www.aasv.org/shap/issues/v5n1/v5n1p21.pdf $>$. Acesso em: 15 nov. 2008.

WAGNER, J.R. et al. Analysis of body composition changes of swine during growth and development. Journal of Animal Science, v.77, p.1442-1466, 1999. Disponível em: <http:// jas.fass.org/cgi/reprint/77/6/1442.pdf $>$. Acesso em: 12 nov. 2008. 